\title{
ИССЛЕДОВАНИЕ ПРОЦЕССА ДЕГИДРИРОВАНИЯ Н-ОКТАНА И Н-ДОДЕКАНА В ПРОТОЧНОЙ СИСТЕМЕ
}

Наши предыдущие сообщения $\left[{ }^{1,2}{ }^{2}\right]$ посвящены исследованию процесса дегидрирования $\boldsymbol{H}$-октана и $\boldsymbol{\mu}$-додекана в паровой фазе на алюмоплатиновых катализаторах методом реакционной газовой хроматографии. В настоящей статье результаты этой работы сопоставляются с данными, полученными при аналогичном исследовании на проточной установке, что представляет методический и практический интерес.

\section{Методика исследования}

Экспериментальная проточная установка состоит из дозирующего устройства, реактора с наружным обогревом (трубчатая печь), системы конденсации и приемников для сбора жидкого катализата и газа катализа. Сырье непрерывно подается в реактор с объемной скоростью $6,5 \varkappa^{-1}$ (в рассчете на исходную жидкость) стеклянным шприцем, который соединен приводом с небольшим синхронным двигателем. Реактор - труба из нержавеющей стали диаметром в свету 12 мм и длиной 500 мм установлен вертикально и верхняя его крышка, закрепляемая на резьбе, снабжена патрубками для подачи сырья и продувки аппарата воздухом, водородом или инертным газом, а также для ввода термопары в слой катализатора. Снизу реактора имеется отверстие для вывода катализата и продувочного газа. Верхняя часть реактора, в которую помещена проволочная насадка, играет роль испарителя. В ней поддерживается постоянная температура $350^{\circ} \mathrm{C}$. Реакционная зона аппарата заполняется катализатором $(0,5 \% \mathrm{Pt}) \mathrm{Al}_{2} \mathrm{O}_{3}$ с размерами гранул 0,250,4 м. ) в количестве 6 мл. Обогревающее устройство реактора рассчитано на варьирование температуры в реакционной зоне в диапазоне от 350 до $420^{\circ}$.

Перед экспериментом производится продувка катализатора аргоном после его восстановления водородом для вытеснения последнего. В эксперименте с «несвежим» катализатором опыту также предшествует продувка инертным газом.

Рассчет времени контакта конвертируемого углеводорода производится по методике из [3] с учетом температуры в реакционной зоне и свободного пространства в объеме катализатора. Исследование жидкого катализата проведено на хроматографе УХ-1; колонка - 20\% полиэтиленгликоля на хромосорбе $P$. Для исследования состава полученного газа иопользовался тот же хроматограф с колонкой, заполненной молекулярными ситами, для разделения легких газов, включая метан (газ- 
носитель аргон), и колонкой, заполненной скваланом на окиси алюминия, - для разделения более тяжелых газообразных углеводородов (газ-носитель гелий или водород). В эксперименте использованы отечественные реактивы (н-октан и н-додекан) марки жч».

При постановке эксперимента с разбавлением паров углеводорода инертным газом (см. ниже) расход последнего измеряется и учитывается при вычислении длительности контакта парогазовой смеси в реакционной зоне.

\section{Результаты и их обсуждение}

Основные результаты первой части эксперимента приведены в табл. 1, где при данной температуре в реакционной зоне опыт со свежим катализатором обозначен I, с использованным, но не подвергнутым регенерации катализатором - II. Первый раздел таблицы посвящен результатам каталитической конверсии н-октана, второй - данным для $\boldsymbol{H}$-додекана.

Как следует из таблицы, максимальный выход октенов - основного продукта прямого дегидрирования н-октана - составляет 18,1-19,0\% и отвечает температурной области $400-420^{\circ}$. Максимальные показатели по выходу додеценов от исходного сырья $(10,4-11,4 \%)$ достигаются при температуре $360-380^{\circ}$ в реакционной зоне. Это значит, что в условиях проточной установки выход октенов практически мало отличается от показателя для импульсного микрореакционного процесса (16\%) в том же интервале температур, однако для выхода складывается менее благоприятно (25\% по весу от исходного сырья в микрореакционной установке).

При использовании свежего катализатора выход суммарного жидкого катализата несколько понижен, а целевых олефинов и газа - повышен. Исключение составляют результаты опытов при минимальной температуре в зоне реакции - $340^{\circ}$ для додекана и $360^{\circ}$ для октана, при которых выход олефинов оказывается повышенным в случае несвежего катализатора. Это явление, очевидно, можно объяснить тем, что при сравнительно низкой температуре период «разработки» катализатора несколько растягивается и последний приобретает максимальную активность по олефинообразованию несколько позднее, частично за временными пределами опыта. При более высокой температуре интенсивнее протекает процесс углеобразования на катализаторе [4,5], активность которого быстро теряется и выход олефинов снижается.

В заключение рассмотрения табл. 1 отметим, что по своему составу жидкие продукты каталитического дегидрирования $H$-октана и $\boldsymbol{H}$-додекана из обенх установок практически не отличаются друг от друга.

$\mathrm{C}$ целью принципиального выяснения возможности дальнейшего воздействия на выходы н-олефинов при дегидрировании соответствующих н-парафинов нами был поставлен дополнительный цикл опытов на той же проточной установке с возвратом реакционной смеси (после конденсации) при том же объемном расходе $\left(6,5 \varphi^{-1}\right)$ и температуре в реакционной зоне $\left(360^{\circ}\right.$ применительно к н-додекану).

Содержание додеценов в исходной смеси - 10,8, суммы низших олефинов от С-7 до С-11-1,0, ароматических углеводородов $-1,1$ вес. \%. Полученный катализат содержит: додеценов 10,9, низших олефинов 1,3 и ароматических углеводородов 1,5 вес. \%. Очевидно, концентрация додеценов в реакционной смеси на уровне $10,8-10,9 \%$ является равновесной для данного процесса в данных условиях. Сам факт ее установления на определенном уровне помогает частично разобраться в мак- 


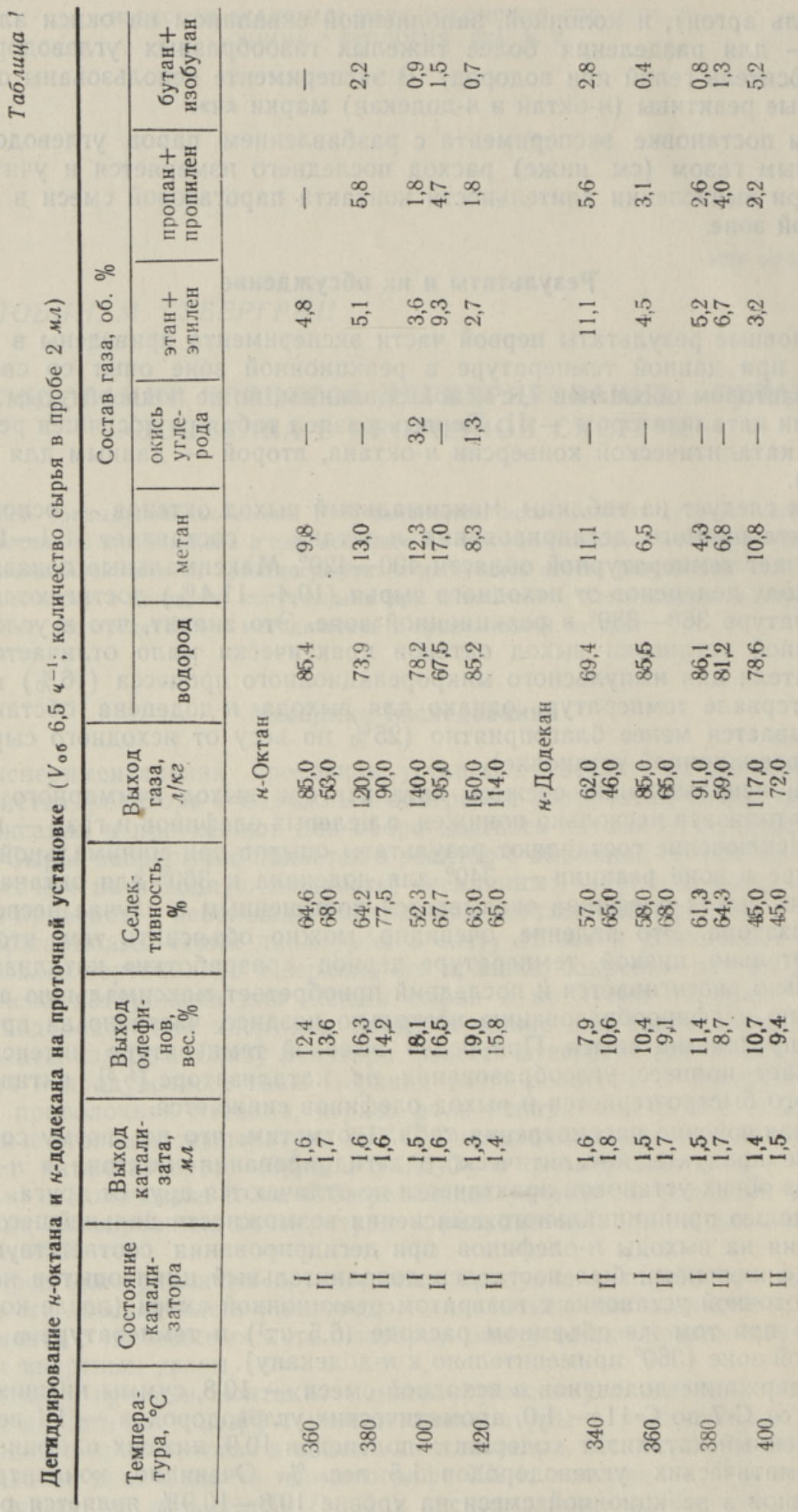


ромеханизме интегрального процесса. Так, если положить в основу об суждения воззрения из [6] на олефин как промежуточный продукт в процессе дегидроциклизации в подобного рода каталитической системе, следует ожидать значительное увеличение выхода ароматических углеводородов при повторной конверсии «первичной» реакционной смеси, поскольку она содержит некоторое, довольно значительное количество олефинов. Однако, так как увеличение выхода ароматических компонентов не находится за пределами погрешности эксперимента и выход олефинов практически остается также неизменным, речь может идти главным образом о равновесии в системе олефин-парафин, хотя процесс и ведется без подачи водорода извне.

В данном случае источником гидрирования образующихся в процессе олефинов может быть водород, адсорбированный катализатором при его восстановлении, равно как и выделяющийся при дегидрировании парафина, дегидроциклизации и образовании кокса на катализаторе. Приведенные соображения подтверждаются результатами исследования состава жидкого катализата, полученного в аналогичном эксперименте, но с дегидрированием не $н$-додекана, а $н$-додецена-1:
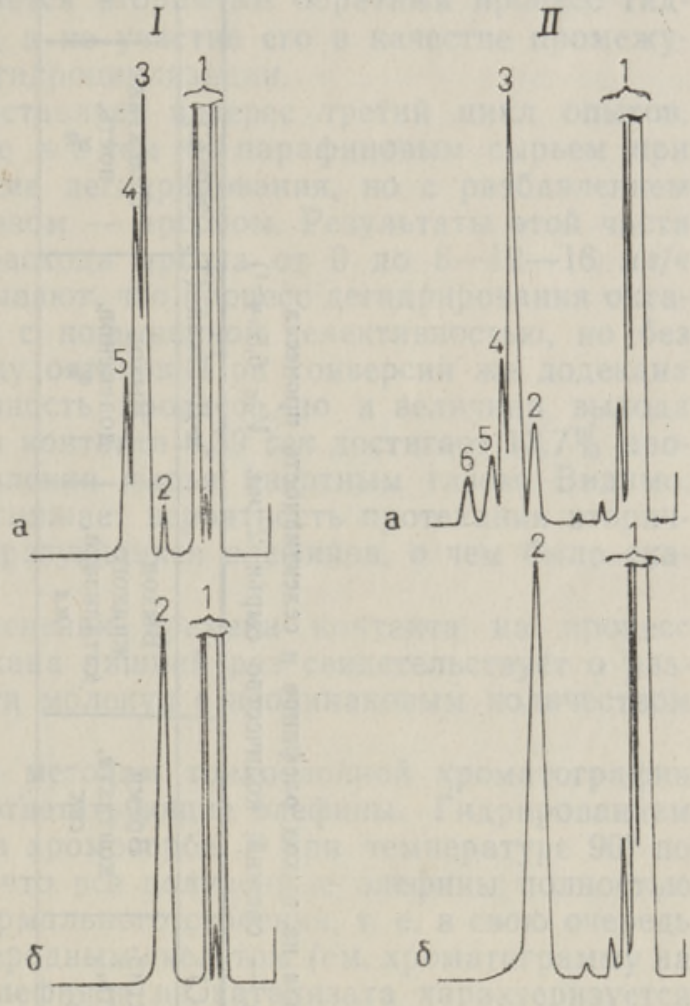

Гидрирование олефинов методом реакционной газовой хроматографии.

1. Смесь октенов. а) 1 - петролейный эфир, 2 - н-октан, 3 - октен-1+октен-4, 4 - октен- 2 , 5 - октен- 3 ; б) 1 - петролейный эфир, 2 н-октан.

II. Смесь додеценов. а) 1 - петролейный эфир, 2 - $н$-додекан, 3 - сумма додецен- 4 , додецен-5, додецен-6, 4 - додецен-1, 5 - додецен-2, 6 додецен- 3 ; б) 1 - петролейный эфир, 2 н-додекан. додецен-1 додецен-2 додецен-3 додецены-4,5,6
$10.0 \%$ сумма низших олефинов

$\begin{array}{lll}6,6 & \text { (от С-7 до С-11) } & 4,2 \% \\ 3,2 & \text { н-додекан } & 29,0\end{array}$

40,0 сумма низших парафинов

(от С-7 до С-11)

1,9 ароматические углеводороды 1,1 прочие неидентифицированные соединения

Таким образом, в изучаемой системе исходный $\mu$-олефиновый углеводород в основном подвергается гидрированию или же вовлекается в реакцию изомеризации двойной связи, а выход ароматических углеводородов - основного продукта реакции дегидроциклизации - остается 
ֻู

ભ

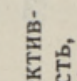

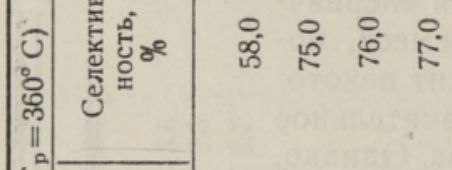

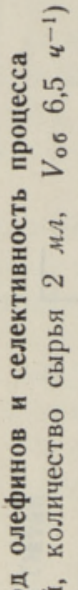

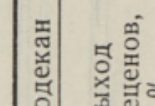

ติ

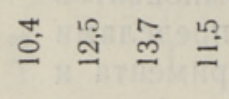

烸

풍$$
\text { (1) }
$$

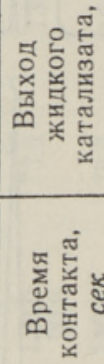

$\stackrel{-10}{-2}$

的

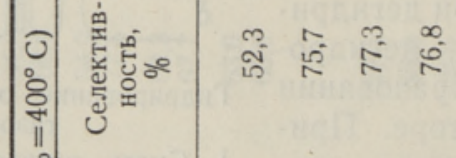

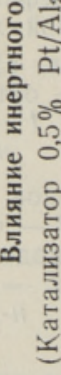

은

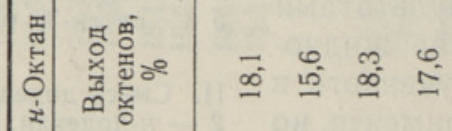

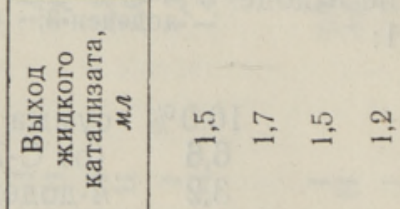

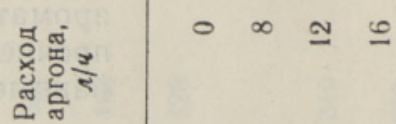


на том же уровне, что и при дегидрировании соответствующего $\mu$-парафнна.

Следовательно, основной причиной, лимитирующей величину выхода $н$-олефина при дегидрировании н-парафина с тем же числом атомов углерода в молекуле, является вторичный обратный процесс гидрирования указанного олефина, а не участие его в качестве промежуточного продукта в реакции дегидроциклизации.

C указанных позиций представляет интерес третий цикл опытов, проведенный в той же установке и с тем же парафиновым сырьем при неизменном оптимальном режиме дегидрирования, но с разбавлением реакционной смеси инертным газом - аргоном. Результаты этой части исследования при изменении расхода аргона от 0 до 8-12-16 нл/4 приведены в табл. 2. Они показывают, что процесс дегидрирования октана протекает в данном случае с повышенной селективностью, но без изменения показателя по выходу октенов. При конверсии же додекана возрастает не только селективность процесса, но и величина выхода додеценов, которая при времени контакта 0,39 сек достигает 13,7\% против 10,4\% в опыте без разбавления сырья инертным газом. Видимо, уменьшение времени контакта снижает вероятность протекания вторичного процесса гидрирования образующихся олефинов, о чем было сқазано выше.

Неодинаковое влияние изменения времени контакта на процесс дегидрирования октана и додекана лишний раз свидетельствует о раз. личной реакционной способности молекул с неодинаковым количеством атомов углерода в цепи.

Из полученных катализатов методом тонкослойной хроматографии на силикагеле [7] выделены соответствующие олефины. Гидрированием их на катализаторе $10 \% \mathrm{Pd}$ на хромосорбе $P$ при темнературе $90^{\circ}$ по методике $\left.{ }^{8}\right]$ удалось доказать, что все полученные олефины полностью конвертируются в парафины нормального строения, т. е. в свою очередь обладают неразветвленным углеродным скелетом (см. хроматограмму на рисунке). Изомерный состав олефинов из катализата характеризуется следующими цифрами:

октены

додецены

октен-2

октен-3

смесь октенов $(1+4)$
30,7 вес. \% додецен-1

13,8 додецен-2

55,5 додецен-2

смесь додеценов

$$
(4+5+6)
$$

18,7 вес. $\%$

11,1

8,8

61,3

Отметим, что в работах $\left[{ }^{9,10}\right]$ также отмечается преимущественный выход олефинов с серединным расположением двойной связи в молекуле.

\section{Выводы}

Сопоставление результатов настоящей работы и предыдущего исследования показывает, что процесс прямого каталитического дегидрирования $H$-парафинов до олефинов соответствующего строения удовлетворительно моделируется с помощью методов импульсной микрореакционной хроматографии.

В обоих случаях оптимальные условия дегидрирования октана отвечают температуре в реакционной зоне на уровне $400-420^{\circ}$, причем в проточной системе максимальный выход октенов 18-19\% по весу от 
сырья отвечает длительности контакта 1,1 сек. Разбавление реакционной смеси инертным газом и сокращение продолжительности контакта не оказывают влияния на выход продуктов дегидрирования, но повышают селективность процесса.

Равновесная концентрация додеценов в реакционной смеси, устанавливаемая в проточной системе на уровне $11 \%$ от сырья, при оптимальном температурном режиме может быть повышена путем разбавления сырья инертным газом и сокращения длительности контакта до 0,39 сек наряду с увеличением селективности процесса. Основной причиной; лимитирующей величину выхода $H$-олефинов при дегидрировании парафинов нормального строения, является протекание обратной реакции гидрирования указанных олефинов, а не их участие в процессе дегидроциклизации.

\section{ЛИ Т Е Р А Т У Р А}

1. Зло бин Н. С., Изв. АН ЭССР, Хим. Геол., 20, 309 (1971).

2. З ло о и н Н. С., Изв. АН ЭССР, Хим. Геол., 22, 84 (1973).

3. Д о лго в Б. Н., Катализ в органической химии. Л. 1959, 46.

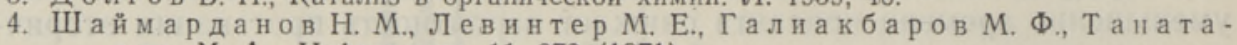
р о в М. А., Нефтехимия, 11, 672 (1971).

5. Курчаткина Т. В., Фомичев Ю. В., Левинтер М. Е., Нефтехимия, 11, 371 (1971)

6. S infelt J. H., Rohrer J. C., J. Chem. and Engng Data, 8, 109 (1963).

7. К а сберг А. Ф., Кл е смен т И. Р., Химия твердого топлива, № 1, 107 (1969).

8. Э й зен О. Г., Ив а нов А. Н., Изв. АН ЭССР, Хим. Геол., 21, 83 (1972).

9. Сергиенко С. Р., Гарбалинский В. А., Медведева В. Д., Петров а А. А., Изв, АН Туркм. ССР, сер. физ., техн., хим. и геол. наук, № 1, 30 (1963).

10. Poth J. F., Abell J. B., Fann in L. W., S cha ef er A. F., Refin. Petrol. Chem. Symp. New York, 1969, 1979, 193-203.

Институт химии
Академии наук Эстонской ССР

Поступила в редакцию 16/V 1973

\section{N. ZLOBIN, M. GUBERGRITS}

\section{n-OKTAANI JA $n$-DODEKAANI DEHUDREERIMISEST LÄBIVOOLUSUSTEEMIS}

Uuriti $n$-oktaani ja $n$-dodekaani dehüdreerimist $\mathrm{Pt} / \mathrm{Al}_{2} \mathrm{O}_{3}$ katalüsaatoril. Tehti kindlaks, et olefiinide saagis oleneb pōhiliselt hüdreerimisreaktsiooni, mitte aga dehüdrotsüklisatsiooni kiirusest. Saadud olefiinidel on lineaarne ehitus, kusjuures ahela keskosas esineb eelistatult kaksikside.

\section{N. ZLOBIN, M. GUBERGRITS}

\section{UNTERSUCHUNG DER DEHYDROGENISATION VON n-OKTAN UND $n$-DODEKAN IM LABORATORIUM}

Der Beitrag bringt die Ergebnisse der Dehydrogenisation von $n$-Oktan und $n$-Dodekan an $\mathrm{Pt} / \mathrm{Al}_{2} \mathrm{O}_{3}$ mit Hilfe einer Laboratoriumanlage.

Es wird gezeigt, daß die Gegenreaktion der Hydrogenisation von entstehenden Olefinen die endgültige Ausbeute der Olefine limitiert.

Die gewonnenen Olefine haben linearen Aufbau. Die Doppelbindung befindet sich meist in der Mitte der Kohlenwasserstoffkette. 